\title{
Thyristor Controlled Series Capasitor Berbasis Adaptive Fuzzy Logic Controller Sebagai Percepatan Peredaman Osilasi Daya Pada Sistem Tenaga
}

\author{
Dwi Agus Prabowo ${ }^{1}$, \\ Istiyo Winarno ${ }^{2}$ \\ Jurusan Teknik Elektro
}

\author{
Fakultas Teknik dan Ilmu Kelautan. \\ Universitas Hang Tuah Surabaya \\ email : agusb234@gmail.com
}

\begin{abstract}
Abstrak - . Pertambahan jumlah penduduk saat ini sangatlah cepat, begitu juga jumlah hunian atau pemukiman semakin merata, dengan ini pemenuhan permintaan kebutuhan akan listrik semakin meluas dan semakin banyak, sehingga membuat penyedia jasa pembangkit energi listrik terus berusaha keras untuk tetap menyediakan energi listrik yang merata dan stabil. Di sisi lain terdapat dampak akibat banyaknya beban pada jaringan listrik yang tidak dapat diperkirakan penggunaannya, naik serta turunnya beban, maka dari itu kestabilitas sistem tenaga harus tetap terjaga, hal ini menjadikan kestabilan sistem tenaga listrik perhatian utama dalam sebuah pengoprasiannya. Tanpa peredaman gangguan yang baik maka gangguan akan terisolasi di dalam sistem dan keluar dari area kestabilannya, sehingga dapat mengakibatkan pengaruh yang lebih buruk seperti pemadaman total. Thyristor Controlled Series Capasitor (TCSC) adalah sebuah perangkat yang dapat digunakan untuk mengatur inmpedansi daya pada sistem tenaga listrik. TCSC memiliki tiga komponen utama antara lain induktor, kapasitor, dan thyristor. Cara kerja TCSC adalah dengan melakukan pengaturan pada sudut penyalaannya, di sini kontroler adaptive fuzzy digunakan sebagai pencari sudut alfa yang terbaik yang dibutuhkan oleh sistem. Dari simulasi perbandingan di dapatkan perbedaan dari kontroler fuzzy dengan adaptive fuzzy yaitu dengan kontroler fuzzy mampu meredam osilasi pada rata-rata waktu 0,68 detik dan dengan kontroler adaptive fuzzy osilasi yang dapat diredam pada waktu 0,56 detik, dengan ini kontroler adaptive fuzzy mampu meredam osilasi 0,12 detik lebih cepat di bandingkan dengan kontroler fuzzy. Sehingga dengan peredaman osilasi ini dapat mengurangi dampak gangguan yang terisolasi di dalam sistem.
\end{abstract}

Kata kunci: Thyristor Controlled Series Capasitor, Osilasi Daya, Adaptive Fuzzy Logic Controller.

\begin{abstract}
The current population growth is very fast, so also the number of settlements more evenly, with this demand fulfillment demand for electricity is increasingly widespread and more, therebr making electric power generation service providers continue to strive to provide uniform and stable electrical energy. On the other hand there is an impact due to the many loads on the network electricity that can not be estimated its use, rise and fall of the load, therefore the power system stability must be maintained, this makes the stability of the power system the main concern in a operating. Without good dampening the disturbance will be isolated in the system and out of the stability area, so it can lead to worse effects such as total blackout. Thyristor Controlled Series Capacitor (TCSC) is a device that can be used to regulate power inmadance of power system. TCSC has three main components such as inductor, capacitor, and thyristor. The way TCSC works is by setting the angle of ignition, here the adaptive fuzzy controller is used as the best alpha-viewer the system needs. From the comparison simulation, the difference of fuzzy controller with adaptive fuzzy with fuzzy controller can reduce oscillation at 0.68 second average time and with fuzzy oscillation adaptive controller that can be muffled at 0.56 seconds, with this adaptive fuzzy controller capable damping oscillations 0.12 seconds faster in comparison with fuzzy controllers. So with this oscillation damping can reduce the impact of isolated disturbances in the system.
\end{abstract}

Keywords: Thyristor Controlled Series Capasitor, Power Osilation, Adaptive Fuzzy Logic Controller.

\section{PENDAHULUAN}

Pertambahan jumlah penduduk saat ini sangatlah cepat, begitu juga jumlah hunian atau pemukiman semakin merata, dengan ini pemenuhan permintaan 
kebutuhan akan listrik semakin meluas dan semakin banyak, sehingga membuat penyedia jasa pembangkit energi listrik terus berusaha keras untuk tetap menyediakan energi listrik yang merata. Di sisi lain terdapat dampak akibat banyaknya beban pada jaringan listrik yang tidak dapat diperkirakan penggunaannya, naik serta turunnya beban, maka dari itu kestabilitasan sistem tenaga harus tetap terjaga, hal ini menjadikan kestabilan sistem tenaga listrik menjadi perhatian utama dalam sebuah pengoprasiannya.

Pada kondisi dan keadaan yang stabil, kecepatan rata-rata untuk semua generator yang harus sama merupakan fakta bahwa kestabilan sistem tenaga menjadi peran penting dalam distribusi kelistrikan. Kondisi seperti ini biasa disebut dengan operasi sinkron pada sebuah sistem interkoneksi. Sebagai contoh, kenaikan atau penurunan beban yang terjadi tiba-tiba, atau akibat rugi pembangkitan menjadi salah satu jenis gangguan yang berpengaruh langsung terhadap sistem. Kestabilan sistem ini diharapkan dapat menjadikan sistem dalam keadaan ideal (steady state) dengan waktu singkat setelah gangguan menghilang.

Gangguan yang menghasilkan tegangan kejutan tiba-tiba pada sistem harus dihilangkan secepat mungkin. Jika tidak, sistem akan terganggu kestabillannya. Tanpa peredaman gangguan yang baik maka sistem akan terganggu dan akan terisolasi dalam gangguan tersebut dan keluar dari area kestabilanya sehingga mengakibatkan pengaruh yang lebih buruk seperti pemadaman total.

Thyristor Controlled Series Capasitor (TCSC) adalah sebuah perangkat yang dapat digunakan untuk mengatur impedansi pada sistem tenaga listrik. TCSC memiliki tiga komponen utama antara lain induktor, kapasitor, dan thyristor. Cara kerja TCSC adalah dengan melakukan pengaturan pada sudut alfa untuk mendapatkan beberapa variasi reaktansi induktif dan kapasitif yang menyebabkan pertukaran daya reaktif secara cepat antara TCSC dan sistem.

Pada tahun 2014, Ahlul. F membahas TCSC yang difungsikan untuk peredaman osilasi daya pada Single Mesin Infinite Bus. Dalam penelitian ini dibahas TCSC yang berperan sebagai pengatur impedansi saluran transmisi yang berfungsi untuk meredam osilasi antara pembangkit menuju ke beban. Agar osilasi dapat diredam secepatnya dibutuhkan kontroler untuk mengatur sudut alpha TCSC. Maka digunakan kontroler Fuzzy agar dapat bekerja secara optimal. [2]

Untuk mengembangkan penelitin sebelumnya maka kontoler Fuzzy akan digantikan dengan kontroler Adaptive Fuzzy, dengan pergantian kontroler ini di harapkan kontroler Adaptive Fuzzy mampu memiliki responsive yang lebih cepat terhadap sistem TCSC untuk meredam osilasi, karena kontroler kontroler Adaptive Fuzzy memiliki keunggulan dalam training data error yang lebih baik dengan menggunakan feedback output data sebagai input error. Sehingga kontroler Adaptive Fuzzy mampu meredam osilasi 0,12 detik lebih cepat dari kontroler Fuzzy.

\section{DASAR TEORI}

\subsection{Ketidakseimbangan Beban}

Yang dimaksud dengan keadaan seimbang adalah suatu keadaan dimana :

- Ketiga vektor arus / tegangan sama besar.

- Ketiga vektor saling membentuk sudut $120^{\circ}$ satu sama lain.

Sedangkan yang dimaksud dengan keadaan tidak seimbang adalah keadaan di mana salah satu atau kedua syarat keadaan seimbang tidak terpenuhi. Kemungkinan keadaan tidak seimbang ada 3 yaitu, [3] :

- Ketiga vektor sama besar tetapi tidak membentuk sudut $120^{\circ}$ satu sama 1 ain.

- Ketiga vektor tidak sama besar tetapi membentuk sudut $120^{\circ}$ satu sama lain.

- Ketiga vektor tidak sama besar, tidak membentuk sudut $120^{\circ}$ satu sama lain.
(A)

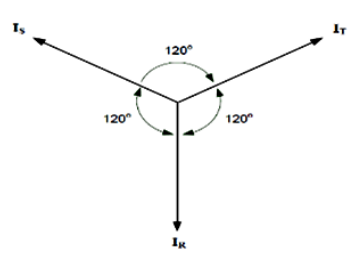

(B)

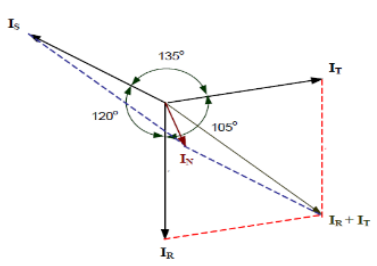

Gambar 1. Vektor Diagram Arus [3]

\section{TCSC (Thyristor Controlled Series Capasitor).}

Thyristor Controlled Series Capacitor (TCSC) adalah alat yang berfungsi sebagai pengendali impedansi dari jaringan transmisi. TCSC merupakan jenis FACTS Devices yang pertama kali dikembangkan. Komponen utama TCSC adalah TCR yang tersusun dari sebuah induktor yang seri dengan thyristor dan diparalel dengan kapasitor. TCSC mampu mengatur reaktansi saluran transmisi dengan melakukan pengaturan sudut penyalaan thyristor. Lebih jelasnya gambar rangkaian TCSC adalah sebagai berikut [4]. 


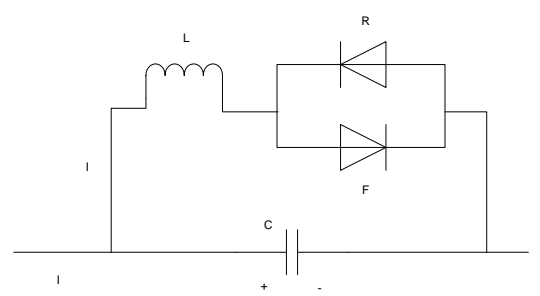

Gambar 2. Rangkaian TCSC [4]

\subsection{Adaptive Fuzzy Logic Controller}

Adaptive fuzzy logic controller adalah perkembangan dari logika fuzzy yang merupakan salah satu dari sistem kecerdasan buatan. Cara kerja kontroler adaptive fuzzy logic controller dapat beradaptasi jika terjadi perubahan input dan output sistem secara tiba-tiba karena pada kontroler ini dilengkapi dengan metode pembelajaran dengan menjumlahkan hasil error output sehingga mendapatkan hasil yang optimal.[1]

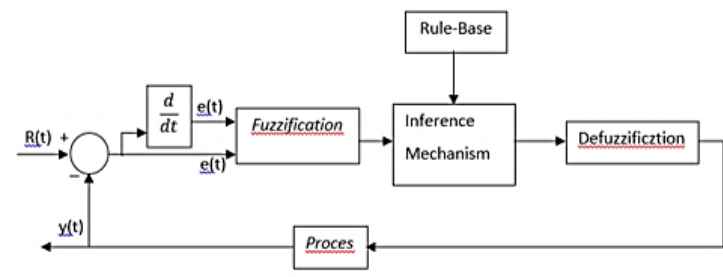

Gambar 3. Struktur Dasar Kontroler Logika Fuzzy [1]

Kontroler logika Adaptive Fuzzy sesungguhnya merupakan sistem yang saling terkait dalam suatu hubungan sebab-akibat, yang membutuhkan spesifikasi hubungan antara masukan dan keluaran, secara umum dinyatakan dengan:

$\operatorname{IF}\left(\mathrm{A}_{1}\right)$ THEN $\left(\mathrm{B}_{1}\right)$

$\operatorname{IF}\left(A_{n}\right)$ THEN $\left(B_{n}\right)$

$\mathrm{A}_{1}, \ldots, \mathrm{A}_{\mathrm{n}}$ adalah antecedent, yaitu masukan yang telah diFuzzyfikasi, sedangkan $\mathrm{B}_{1}, \ldots, \mathrm{B}_{\mathrm{n}}$ adalah consequent, yaitu aksi kontrol (keluaran). Hubungan antara antecedent dan consequent disebut aturan (rule).

Proses untuk mendapatkan aksi keluaran dari suatu kondisi masukan, dengan mengikuti rule-rule yang telah ditetapkan disebut inference atau reasoning (pengambilan keputusan). Keputusan yang dihasilkan dari proses reasoning ini masih dalam bentuk Fuzzy, yaitu berupa derajat keanggotaan keluaran.

Kontroler yang berbasis logika Adaptive Fuzzy harus melalui beberapa tahapan sebelum sampai ke plant. Tahapan-tahapan tersebut antara lain : Kuantisasi,
Fuzzifictioni, Penentuan rule base dan Inference, Defuzzifikasi kemudian Proses data.[1]

\section{METODE PENELITIAN}

Dalam perancangan penelitian ini peneliti akan menjelaskan tahap dan struktur kerja dari TCSC dengan menggunakan kontroler fuzzy dan kontroler adaptive fuzzy sebagai peredam osilasi pada beban tidak seimbang. Disini peneliti akan membandingkan serta mengembangkan pada bagian kontrolernya. Dari peneitian sebelumnya TCSC dengan kontroler fuzzy memang cukup baik dalam meredam osilasi namun masih belum mendekati 0 , atas dasar itu peneliti akan mengembangkannya.

\subsection{Desain TCSC (Thyristor Controlled Series Capasitor)}

TCSC adalah perangkat elektronika daya yang terdiri atas TCR ( Thyristor Controlled Reactor) yang dihubung paralel dengan kapasitor fix. Operasi kerja TCSC yang dapat bekerja pada mode induktif ataupun kapasitif berperan penting pada kompensasi impedansi jaringan. Berikut ini adalah gambar desain simulasi TCSC dengan menggunakan Matlab Simulink. Desain all system Simulasi TCSC dapat dilihat gambar berikut ini.

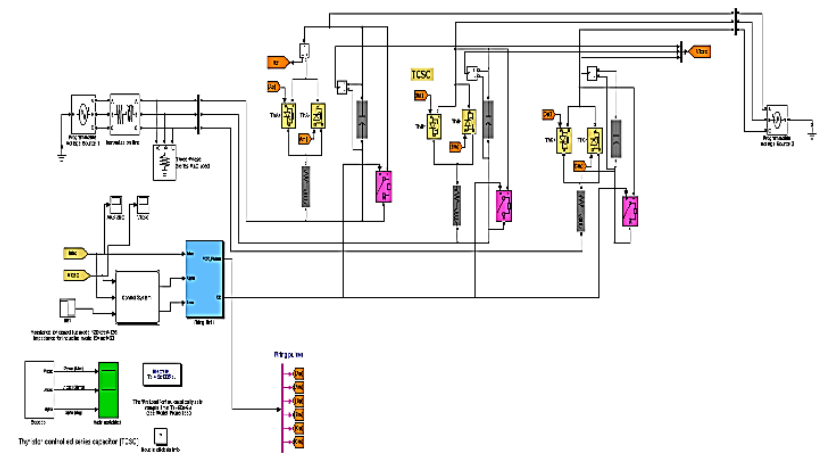

Gambar 4. All System TCSC Simulation.

\subsection{Perancangan Kontroler Logika Adaptive Fuzzy}

Pada penelitian ini menggunakan kontroler Adaptive Fuzzy yang berfungsi pada pengaturan sudut penyalaan dari thyristor. Penggunaan kontroler Adaptive Fuzzy diharapkan dapat mempercepat proses peredaman osilasi daya. Setelah proses fuzzification, keluaran dari fuzzification tadi masuk ke proses Inference Mechanisme dengan mempertimbangkan rulebase serta membership function setelah itu diproses di deFuzzyfication untuk merubah variable Adaptive Fuzzy ke bentuk keluaran akhir dalam sistem ini yaitu sudut penyalaan dari thyristor (thyristor's firing angle). 
Berikut adalah diagram simulink kontroler adaptive fuzzy yang digunakan dalam penelitian.

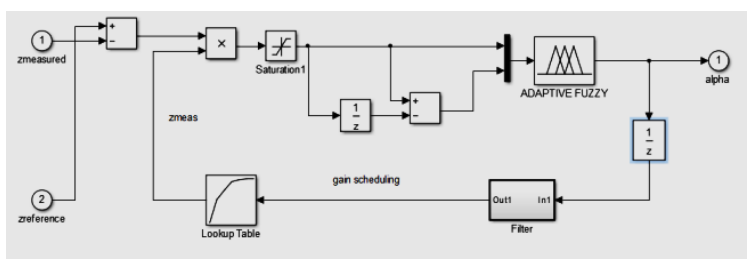

Gambar 5. Diagram Simulink Kontroler Adaptive Fuzzy.

Rule base yang digunakan dalam kontroler Adaptive Fuzzy ini memiliki 49 rule base berikut ini adalah tabel dari rule base yang digunakan.

Tabel 1. Rule base kontroler Adaptive Fuzzy

\begin{tabular}{|c|c|c|c|c|c|c|c|}
\hline 口e/e & NB & NM & NS & ZE & PS & PM & PB \\
\hline NB & NB & NB & NB & NB & NM & NS & ZE \\
\hline NM & NB & NM & NM & NM & NS & ZE & PS \\
\hline NS & NB & NM & NS & NS & ZE & PS & PM \\
\hline ZE & NB & NM & NS & ZE & PS & PM & PB \\
\hline PS & NM & NS & ZE & PS & PS & PM & PB \\
\hline PM & NS & ZE & PS & PM & PM & PM & PB \\
\hline PB & ZE & PS & PM & PB & PB & PB & PB \\
\hline
\end{tabular}

\section{HASIL DAN PEMBAHASAN}

Berikut ini adalah hasil simulasi TCSC menggunakan kontroler Fuzzy dan Adaptive Fuzzy dengan perubahan amplitudo [ 10,51 ] pada beban kapasitif yang bernilai $12 \mathrm{e} 3 \mathrm{Var}, 20 \mathrm{e} 3 \mathrm{Var}, 50 \mathrm{e} 3 \mathrm{Var}$ :

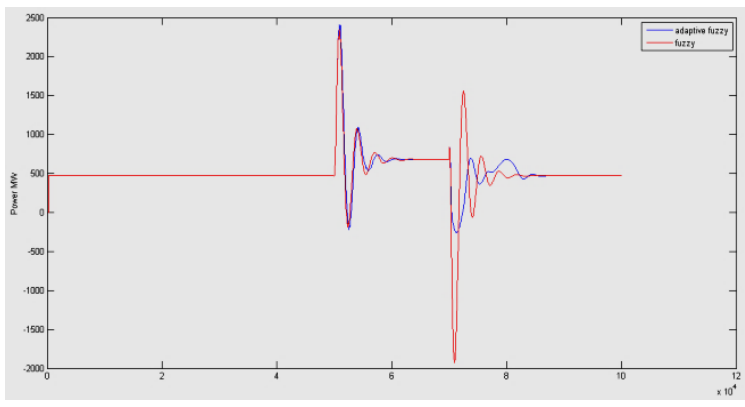

Gambar 7. Hasil Simulasi Daya menggunakan Kontroler Fuzzy dan Adaptive Fuzzy pada Beban Induktif
Berikut ini adalah hasil simulasi TCSC menggunakan kontroler Fuzzy dan Adaptive Fuzzy dengan perubahan amplitudo [ 10,71 ] pada beban kapasitif yang bernilai 20e3 Var:

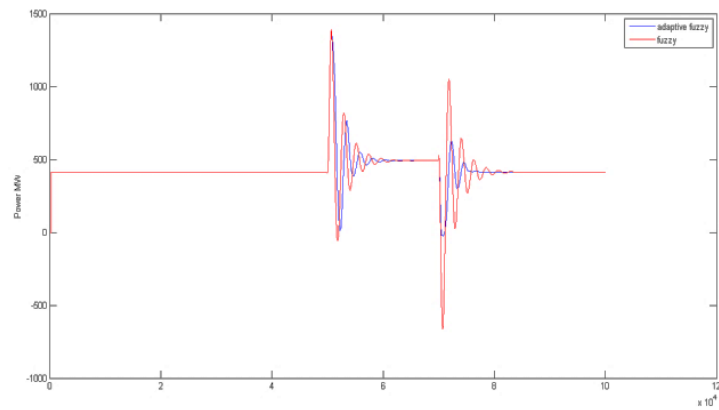

Gambar 8. Hasil Simulasi Daya menggunakan Kontroler Fuzzy dan Adaptive Fuzzy pada Beban Kapasitif

Data hasil simulasi peredaman osilasi daya menggunakan TCSC kontroler Fuzzy dan Adaptive Fuzzy ditunjukkan pada tabel 1 berikut ini :

Tabel 1. Data hasil simulasi TCSC menggunakan kontroler Fuzzy dan Adaptive Fuzzy

\begin{tabular}{|c|c|c|c|c|c|}
\hline & \multirow{3}{*}{$\begin{array}{c}\text { Beban } \\
\text { (Var) }\end{array}$} & \multicolumn{4}{|c|}{$\begin{array}{c}\text { Pencapaian Steady State Setelah } \\
\text { Terjadi Osilasi/ Detik ke }\end{array}$} \\
\hline & & \multicolumn{2}{|c|}{$\begin{array}{c}\text { Osilasi Pada detik } \\
2,5 \\
\end{array}$} & \multicolumn{2}{|c|}{$\begin{array}{c}\text { Osilasi Pada detik } \\
\mathbf{3 , 5} \\
\end{array}$} \\
\hline & & $\begin{array}{c}\text { Fuzz } \\
y\end{array}$ & $\begin{array}{c}\text { Adaptive } \\
\text { Fuzzy }\end{array}$ & Fuzzy & $\begin{array}{l}\text { Adaptiv } \\
\text { e Fuzzy }\end{array}$ \\
\hline \multicolumn{6}{|c|}{ Perubahan Amplitudo [ $1, p .51$ ] } \\
\hline \multirow{3}{*}{$\begin{array}{l}\text { Beban } \\
\text { Induktif }\end{array}$} & $12 \mathrm{e} 3$ & 0,7 & 0,6 & 0,6 & 0,5 \\
\hline & $20 \mathrm{e} 3$ & 0,68 & 0,52 & 0,7 & 0,75 \\
\hline & $50 \mathrm{e} 3$ & 0,78 & 0,53 & 0,62 & 0,78 \\
\hline \multirow{3}{*}{$\begin{array}{l}\text { Beban } \\
\text { Kapasiti } \\
\text { f }\end{array}$} & $12 \mathrm{e} 3$ & 0,68 & 0,62 & 0,61 & 0,51 \\
\hline & $20 \mathrm{e} 3$ & 0,72 & 0,51 & 0,7 & 0,53 \\
\hline & $50 \mathrm{e} 3$ & 0,72 & 0,68 & 0,63 & 0,38 \\
\hline \multicolumn{6}{|c|}{ Perubahan Amplitudo [ $\left.\begin{array}{llll}1 & 0.7 & 1\end{array}\right]$} \\
\hline \multirow{3}{*}{$\begin{array}{l}\text { Beban } \\
\text { Induktif }\end{array}$} & $12 \mathrm{e} 3$ & 0,57 & 0,54 & 0,8 & 0,48 \\
\hline & $20 \mathrm{e} 3$ & 0,7 & 0,68 & 0,68 & 0,74 \\
\hline & $50 \mathrm{e} 3$ & 0,63 & 0,63 & 0,84 & 0,72 \\
\hline \multirow{3}{*}{$\begin{array}{l}\text { Beban } \\
\text { Kapasiti } \\
\text { f }\end{array}$} & $12 \mathrm{e} 3$ & 0,58 & 0,53 & 0,53 & 0,5 \\
\hline & $20 \mathrm{e} 3$ & 0,63 & 0,62 & 0,72 & 0,32 \\
\hline & $50 \mathrm{e} 3$ & 0,67 & 0,62 & 0,64 & 1,1 \\
\hline \multicolumn{6}{|c|}{ Perubahan Amplitudo [ $\left.\begin{array}{llll}1 & 0.85 & 1\end{array}\right]$} \\
\hline \multirow{3}{*}{$\begin{array}{l}\text { Beban } \\
\text { Induktif }\end{array}$} & $12 \mathrm{e} 3$ & 0,75 & 0,56 & 0,64 & 0,3 \\
\hline & $20 \mathrm{e} 3$ & 0,75 & 0,7 & 0,7 & 0,34 \\
\hline & $50 \mathrm{e} 3$ & 0,82 & 0,7 & 0,7 & 0,62 \\
\hline \multirow{3}{*}{$\begin{array}{l}\text { Beban } \\
\text { Kapasiti } \\
\text { f }\end{array}$} & $12 \mathrm{e} 3$ & 0,6 & 0,58 & 0,62 & 0,36 \\
\hline & $20 \mathrm{e} 3$ & 0,68 & 0,7 & 0,67 & 0,62 \\
\hline & $50 \mathrm{e} 3$ & 0,7 & 0,62 & 0,82 & 0,6 \\
\hline \multirow{2}{*}{\multicolumn{2}{|c|}{$\begin{array}{c}\text { Waktu Peredaman } \\
\text { Rata-rata }\end{array}$}} & \multicolumn{2}{|c|}{ Kontroler Fuzzy } & \multicolumn{2}{|c|}{0,68 detik } \\
\hline & & \multicolumn{2}{|c|}{$\begin{array}{l}\text { Kontroler } \\
\text { Adaptive Fuzzy }\end{array}$} & \multicolumn{2}{|c|}{0,56 detik } \\
\hline
\end{tabular}

Dari tabel 1 dapat di lihat osilasi daya pada detik 2,5 yang menggunakan kontroler fuzzy rata-rata mencapai steady state pada detik ke 0.68 sedangkan dengan menggunakan kontroler adaptive fuzzy pada 
detik ke 0.6. Pada osilasi atau gangguan daya pada detik 3.5 yang menggunakan kontroler fuzzy terlihat rata-rata mencapai steady state pada detik ke 0,67 dan yang menggunakan kontroler adaptive fuzzy pada detik ke 0,56. Hal ini membuktikan bahwa TCSC menggunakan kontroler Adaptive Fuzzy lebih efektif dibanding kontroler Fuzzy karena kemampuan peredaman osilasi yang relatif singkat dengan selisih waktu rata-rata 0,12 detik.

\section{KESIMPULAN}

Dari hasil simulasi yang dilakukan dapat disimpulkan bahwa TCSC dengan menggunakan kedua kontroler tersebut dapat bekerja dengan baik, namun terdapat perbedaan dalam mengatasi gangguan osilasi tersebut di sini kontroler Adaptive Fuzzy mampu meredam osilasi dengan rata-rata 0,6 detik pada perubahan amplitudo detik ke 2,5 dan pada perubahan amplitudo detik ke 3,5 dengan rata-rata 0,56 detik, sedangkan kontroler Fuzzy dapat meredam osilasi dengan waktu rata-rata 0,68 detik pada perubahan amplitudo detik ke 2,5 dan pada perubahan amplitudo detik 3,5 dengan rata-rata 0,67 detik. Hal ini menunjukan bahwa kontroler adaptive fuzzy lebih baik serta lebih cepat dalam meredam osilasi dibandingkan dengan kontroler fuzzy dalam meredam osilasi, yaitu dengan terpaut selisih waktu rata-rata 0,12 detik. Jika dibandingkan dengan kontroler fuzzy bentuk gelombang yang teredan oleh kontroler adaptive fuzzy lebih rendah. Sehingga semakin cepat peredaman yang dilakukan oleh kontrol sistem maka gangguan yang terjadi tidak akan terisolasi di dalam sistem dan kualitas daya semakin meningkat dalam penyaluran tenaga listrik.

\section{DAFTAR PUSAKA}

[1] Agoeng, R. 2011. Fuel Injection Control System of Mitsubishi 4G63 with Adaptive Fuzzy Logic Control Method [Skripsi]. Surabaya : Institut Teknologi 10 November Surabaya.

[2] Ahlul F. 2014. Fuzzy Logic Controller pada Thyristor Controlled Series Capasitor (TCSC) Sebagai Peredam Osilasi Daya pada Sistem Tenaga Listrik [Skripsi]. Surabaya : Universitas Hang Tuah.

[3] Alif F. 2013. Penggunaan Mini DVR Sebagai Pemulih Tegangan Untuk Pengganti UPS Menggunakan PI Controller [Skripsi]: Jember: Universitas Jember.

[4] M.Kuncoro. 2009. Simulasi Peredaman Interaksi Torsi Subsynchronous Resonance Pada Sistem
Tenaga Listrik Dengan Menggunakan Thyristor Controlled Series Capasitor [Skripsi]. Depok : Universitas Indonesia. 